\title{
Micromolecular methods for diagnosis and therapeutic strategy: a case study
}

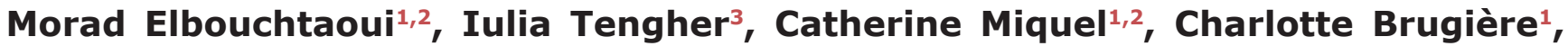 \\ Amélie Benbara ${ }^{4}$, Laurent Zelek ${ }^{5,7}$, Marianne Ziol ${ }^{3,5,6}$, Fatiha Bouhidel ${ }^{1,2}$, Anne \\ Janin $^{1,2}$, Guilhem Bousquet ${ }^{1,5,7, *}$ and Christophe Leboeuf ${ }^{1, *}$ \\ ${ }^{1}$ Université Paris Diderot, Inserm, UMR_S1165, Paris, France \\ ${ }^{2}$ Pathology Department, Hôpital St Louis, APHP, Paris, France \\ ${ }^{3}$ Pathology Department, Hôpital Jean Verdier, APHP, Bondy, France \\ ${ }^{4}$ Obstetrics and Gynecology Department, Hôpital Jean Verdier, APHP, Bondy, France \\ ${ }^{5}$ Université Paris 13, Villetaneuse, France \\ ${ }^{6}$ Inserm UMR_S1162, Paris, France \\ ${ }^{7}$ Oncology Department, Hôpital Avicenne, APHP, Bobigny, France \\ ${ }^{*}$ Co-senior authors \\ Correspondence to: Guilhem Bousquet, email: guilhem.bousquet@aphp.fr \\ Christophe Leboeuf, email: christophe.leboeuf@univ-paris-diderot.fr \\ Keywords: HER2 overexpressing breast cancer; micromethods; cancer therapy; laser-microdissection; trastuzumab-based \\ treatment \\ Received: July 03, $2017 \quad$ Accepted: April 03, $2018 \quad$ Published: April 27, 2018 \\ Copyright: Elbouchtaoui et al. This is an open-access article distributed under the terms of the Creative Commons Attribution Li- \\ cense 3.0 (CC BY 3.0), which permits unrestricted use, distribution, and reproduction in any medium, provided the original author \\ and source are credited.
}

\section{ABSTRACT}

An intraductal carcinoma, $55 \mathrm{~mm}$ across, was diagnosed on a total mastectomy in a 45-year-old woman. The $\mathbf{2}$ micro-invasive areas found were too small for reliable immunostainings for estrogen, progesterone, and HER2 receptors. In the sentinel lymph-node, a subcapsular tumor embole of about $\mathbf{5 0}$ cancer cells was identified on the extemporaneous cryo-cut section, but not on further sections after paraffinembedding of the sample.

Considering this tumor metastatic potential, we decided to assess HER2 status on the metastatic embole using pathological and molecular micro-methods. We lasermicrodissected the tumor cells, extracted their DNA, and performed droplet-digitalPCR (ddPCR) for HER2 gene copy number variation. The HER2/RNaseP allele ratio was 5.2 in the laser-microdissected tumor cells, similar to the 5.3 ratio in the HER2overexpressing breast cancer cell line BT-474.

We thus optimized the adjuvant treatment of our patient and she received a trastuzumab-based adjuvant chemotherapy.

\section{INTRODUCTION}

HER2 overexpressed breast cancers are accounting for 15 to $20 \%$ of breast cancers [1], and strongly benefit from anti-HER2 treatment mainly trastuzumab-based chemotherapies $[2,3]$.

Robust methods have been developed within the last 20 years to accurately determine HER 2 status, including immunohistochemistry (IHC) and fluorescence in situ hybridization (FISH). An international consensus updated in 2013 has defined the criteria for HER2 overexpression and/or gene amplification [4]. However, these standard methods have still some limitations, typically small invasive foci in a primary tumor or a lymph node micrometastasis.

Digital droplet polymerase chain reaction (ddPCR) is a more recent technology that has been tested for the determination of HER2 gene copy number status in breast 
and gastric cancers [5-8]. Preliminary studies on large invasive components of breast or gastric cancers have reported an excellent concordance between ddPCR and FISH $[5,6]$.

It has not been evaluated yet for small invasive foci or micro-metastatic cell clusters.

In this study, we used this methodology in a clinical situation of micro-invasive breast cancer with a lymphnode micrometastasis and an undetermined HER2 status, to optimize the patient's treatment.

\section{RESULTS}

\section{Micromolecular methods enabled to determine HER2 status of a breast cancer lymph-node micro-metastasis}

An intra-ductal carcinoma, $55 \mathrm{~mm}$ across, was diagnosed on a total mastectomy in a 45 -year-old woman. The 2 micro-invasive areas found $(<1 \mathrm{~mm}$ each) were too small for reliable immunostainings for estrogen, progesterone, and HER2 receptors. In the unique sentinel lymph-node identified using both isotopic and colorimetric methods, a subcapsular cluster of about 50 cohesive cancer cells was identified on the extemporaneous cryocut section (Figure 1A), but not on further sections after paraffin-embedding of the sample. The largest diameter of this cancer cell cluster was $220 \mu \mathrm{m}$, which defines a micrometastasis ( $\mathrm{pN} 1 \mathrm{mi}$ ) according to UICC international classification [9]. The tumor was thus classified pT1miN1miM0.

Considering this tumor metastatic potential, we decided to assess HER2 status on the metastatic micrometastasis using pathological and molecular micromethods. On the $5 \mu \mathrm{m}$-thick frozen tissue section of the sentinel lymph node, we laser-microdissected the tumor cells on a total area of $21492 \mu \mathrm{m}^{2}$, extracted their DNA, and performed droplet-digital-PCR (ddPCR) for HER2 and $R N A s e P$ gene copy number variation. We chose RNAseP and not centromere of Ch17 (CEP17) as reference gene, due to the limited quantity of available material. Contrary to FISH, ddPCR cannot determine the absolute copy number of $H E R 2$, and a polysomy 17 would have masked a HER2 amplification.

The HER2/RNaseP allele ratio was 5.2 in the laser-microdissected tumor cells, similar to the 5.3 ratio in the HER2-overexpressing breast cancer cell line BT474 (Figure 1B). HER2 was also overexpressed in the intra-ductal component (Figure 1C). Considering the high metastatic potential (pN1mi), the amplified status of $H E R 2$ with a ratio $H E R 2 / R N a s e P$ over 5 , and the patient's own wish to decrease her relapse risk as far as possible, we decided to perform a trastuzumab-based adjuvant chemotherapy according to national guidelines [10].

\section{Laser-microdissection combined with ddPCR is a reliable method to determine HER 2 status on small numbers of breast cancer cells}

Though ddPCR has not yet been validated by consensus guidelines, several recent studies have shown that ddPCR has excellent correlation with immunohistochemistry or fluorescence in situ hybridization for the determination of HER2 status on large tissue sections of formalin-fixed cancer samples $[5,6]$. We aimed to demonstrate that this was also true for small clusters of cancer cells such as micro-invasive foci or micrometastases.

We first performed a dilution assay with BT-474 HER2-overexpressing cancer cell line. Using lasermicroselection to precisely count the total number of cells tested, we assessed HER 2 copy number status on 1, 5, 10,20 and 50 cells. We demonstrated that 10 cells were sufficient to accurately determine HER 2 copy number status (Figure 2).

Then, we applied our methodology to formalin-fixed tissue sections from biopsies of nine breast cancers with known HER2 status using both immunohistochemistry and FISH. Since we did not have entire cells on tissue sections but only nucleus sections, a reliable result could be obtained only with a minimum of 50 laser-microdissected cancer cells. With this cut-off, we accurately determined HER 2 status compared to immunohistochemistry. Further, in all 9 cases, the range of HER2 gene amplification was comparable to that determined using FISH (Table 1).

In the case of patient 4 (underlined in grey in Table 1), using FISH, the ratio HER2/CEP17 was $<2$ while $H E R 2$ copy number was high, of 15.1 . The status of this breast cancer was thus amplified according to 2013 consensus [4]. Using ddPCR, the ratio HER2/CEP17 was 1.5 because of the polysomy 17 and could not detect HER 2 amplification. By contrast, the ratio HER2/RNAseP of 3 was concordant with the amplified HER2 status.

\section{Assessment of HER2 status on in situ breast cancers with undetermined micro-invasive component}

We first assessed the frequency of in situ breast carcinoma with undetermined micro-invasive component. After interrogation of Saint-Louis hospital tumor bank register from January 2015 to December 2016, we identified 1282 patients with breast surgery for an invasive and/or in situ carcinoma, 147 of them with an in situ component. When we only retained in situ carcinomas with a micro-invasive component (i.e. $<2 \mathrm{~mm}$ according to international definition), they concerned 17 patients. Seven of them had undetermined HER2 status because of an insufficient quantity of cancer cells with invasive features ( $5 \%$ of cases of in situ carcinomas over 2 years in our Cancer Center) (Figure 3). 


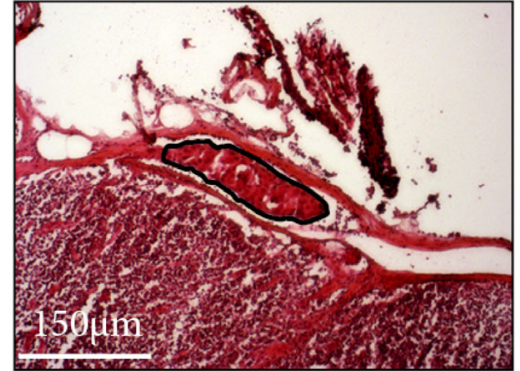

Before

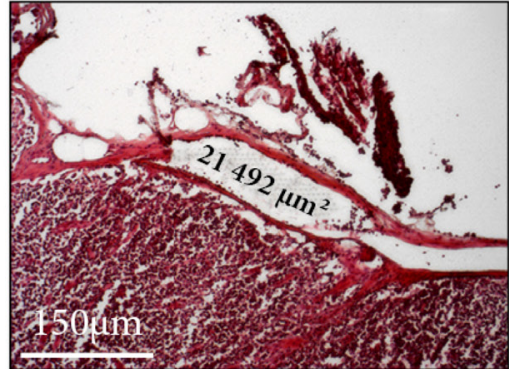

After

B

HER2 gene copy number variations

Control overexpressing HER2

Control non overexpressing HER2

Laser microdissected tumor cells

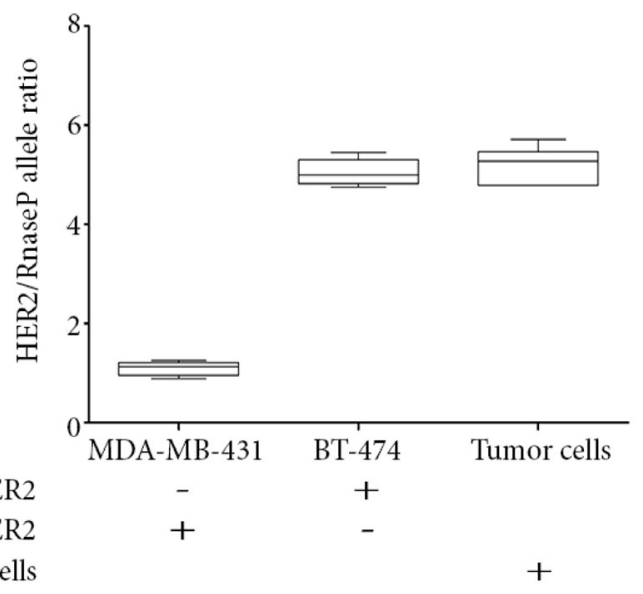

C In situ carcinoma

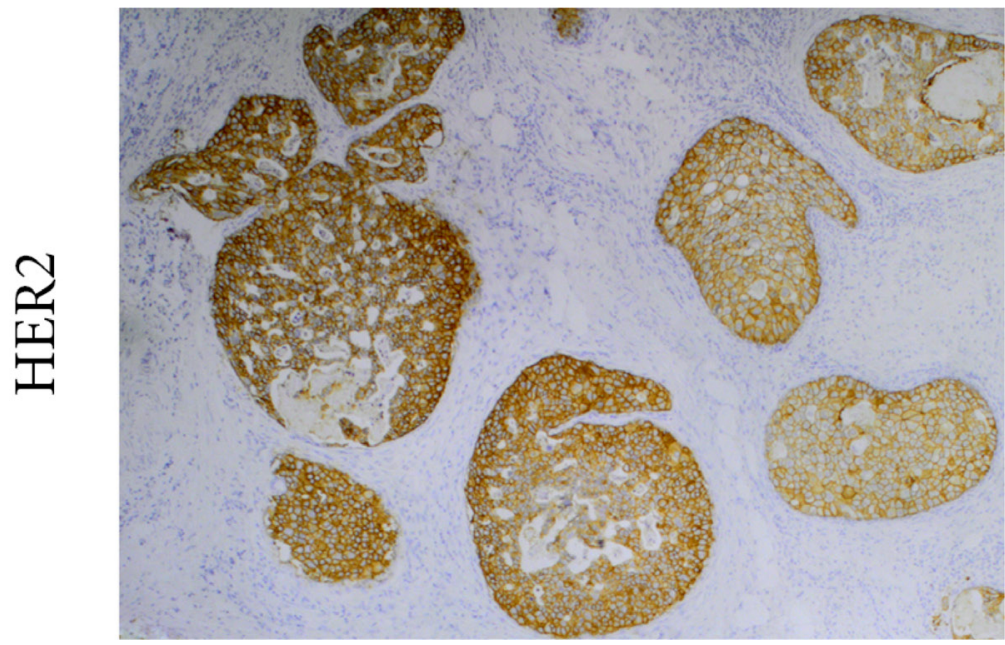

Figure 1: (A) Laser microdissection of the intra-lymphatic embole of tumor cells. Lymph node section, hematein-eosin staining. (B) HER2 gene copy number of the laser-microdissected tumor cells. Digital droplet PCR method, using BT-474 and MDA-MB-431 cell lines respectively as positive and negative controls. (C) HER2 immunostaining on the ductal carcinoma in situ component. In situ carcinoma cells are overexpressing HER2. 
Table 1: Comparison of ddPCR and standard methods for assessment of HER2 status on breast cancer

\begin{tabular}{lccccc}
\hline \multirow{2}{*}{ Patient } & IHC HER2 score & \multicolumn{2}{c}{ FISH } & \multicolumn{2}{c}{ ddPCR } \\
\cline { 3 - 6 } & & HER2 copy number & ratio HER2/ & ratio HER2/ & ratio HER2/ \\
CEP17 & RNAseP \\
\hline Patient 1 & 0 & 2.1 & $\mathbf{1}$ & $\mathbf{0 . 3}$ & 0.4 \\
Patient 2 & 1 & 2.2 & $\mathbf{1}$ & $\mathbf{0 . 8}$ & 0.3 \\
Patient 3 & 2 & 3.2 & $\mathbf{1 . 2}$ & $\mathbf{0 . 9}$ & 0.4 \\
Patient 4 & 2 & 15.1 & $\mathbf{1 . 8}$ & $\mathbf{1 . 5}$ & 3 \\
Patient 5 & 2 & 5.9 & $\mathbf{3}$ & $\mathbf{4 . 2}$ & 4.4 \\
Patient 6 & 2 & 7.9 & $\mathbf{3 . 9}$ & $\mathbf{4}$ & 3.3 \\
Patient 7 & 3 & 15.4 & $\mathbf{5 . 7}$ & $\mathbf{9}$ & 5.3 \\
Patient 8 & 3 & 21.1 & $\mathbf{1 0 . 2}$ & $\mathbf{8 . 5}$ & 7 \\
Patient 9 & 3 & 21.7 & $\mathbf{1 0 . 3}$ & $\mathbf{9 . 4}$ & 12 \\
\hline
\end{tabular}

IHC: immunohistochemistry.

FISH: fluorescence in situ hybridization.

ddPCR: digital droplet PCR.

A

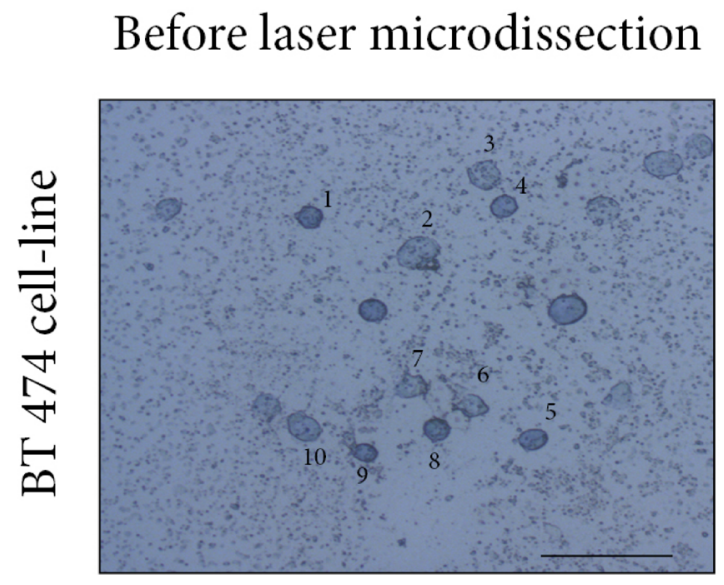

Laser microdissection of 10 cells

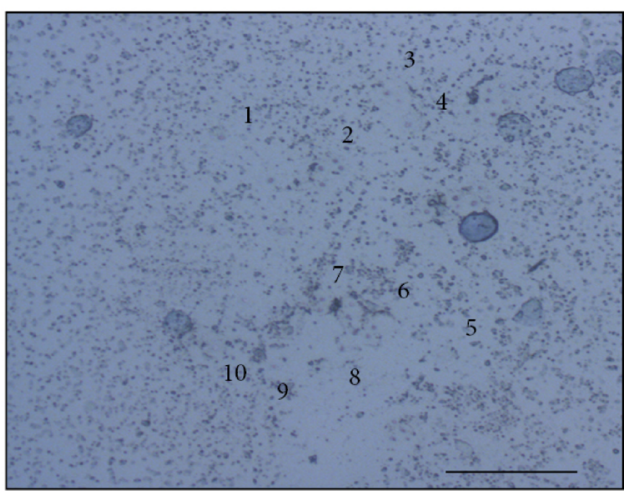

B

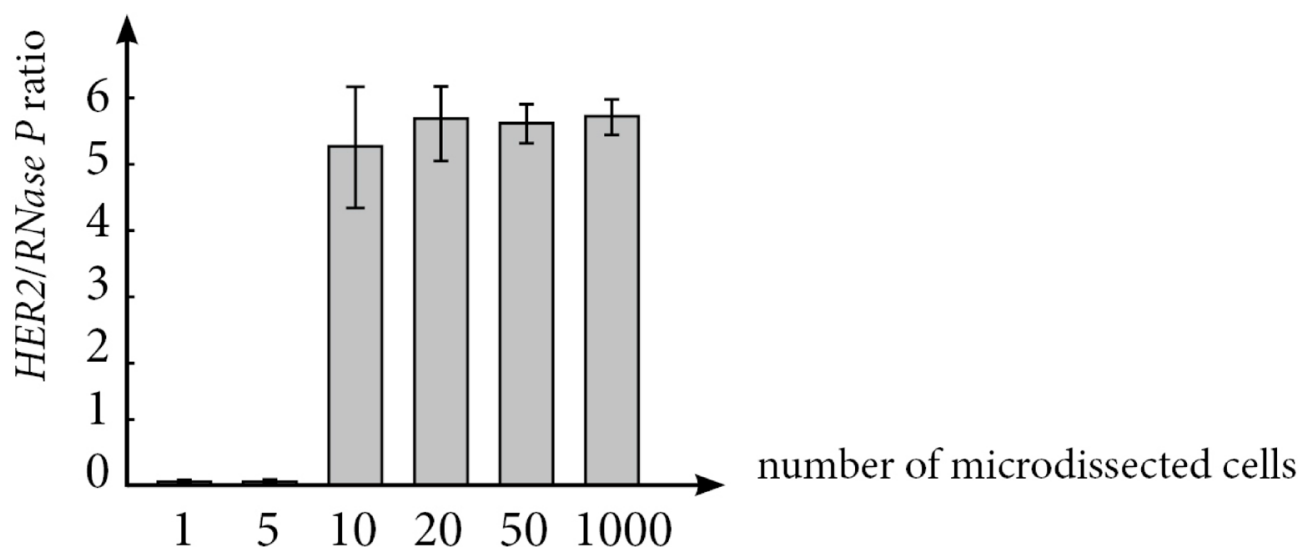

Figure 2: (A) Laser-microdissection in liquid medium of BT474 breast cancer cells enables to precisely count and select 10 live cells. (B) A minimum of 10 live cells are required to accurately determine HER2 copy number status. 
Using our methodology for HER2 copy number assessment, we were able to determine HER2 status for 6 of the 7 cases, and HER2 was amplified in 2 cases (Figure 4 and Table 2). For one case, we could not reach the cut-off of 50 laser-microdissected cells on the microinvasive component.

\section{DISCUSSION}

In the case of our patient, a mere follow-up would have been the rule on the basis of initial clinico-biological data. Tumor cell laser-microdissection on the only sentinel lymph-node section including a lymphatic micrometastasis enabled us to demonstrate HER2 amplification in these tumor cells, and to optimize the patient's treatment with trastuzumab-based adjuvant chemotherapy in line with international guidelines [10]. In the absence of lymphnode involvement, adjuvant chemotherapy is not fully recommended for HER2-overexpressing breast cancers of less than $5 \mathrm{~mm}$ (pT1mi and pT1a) [10, 11]. Here, for decision treatment, we considered two biological characteristics: the high metastatic potential of this micro-

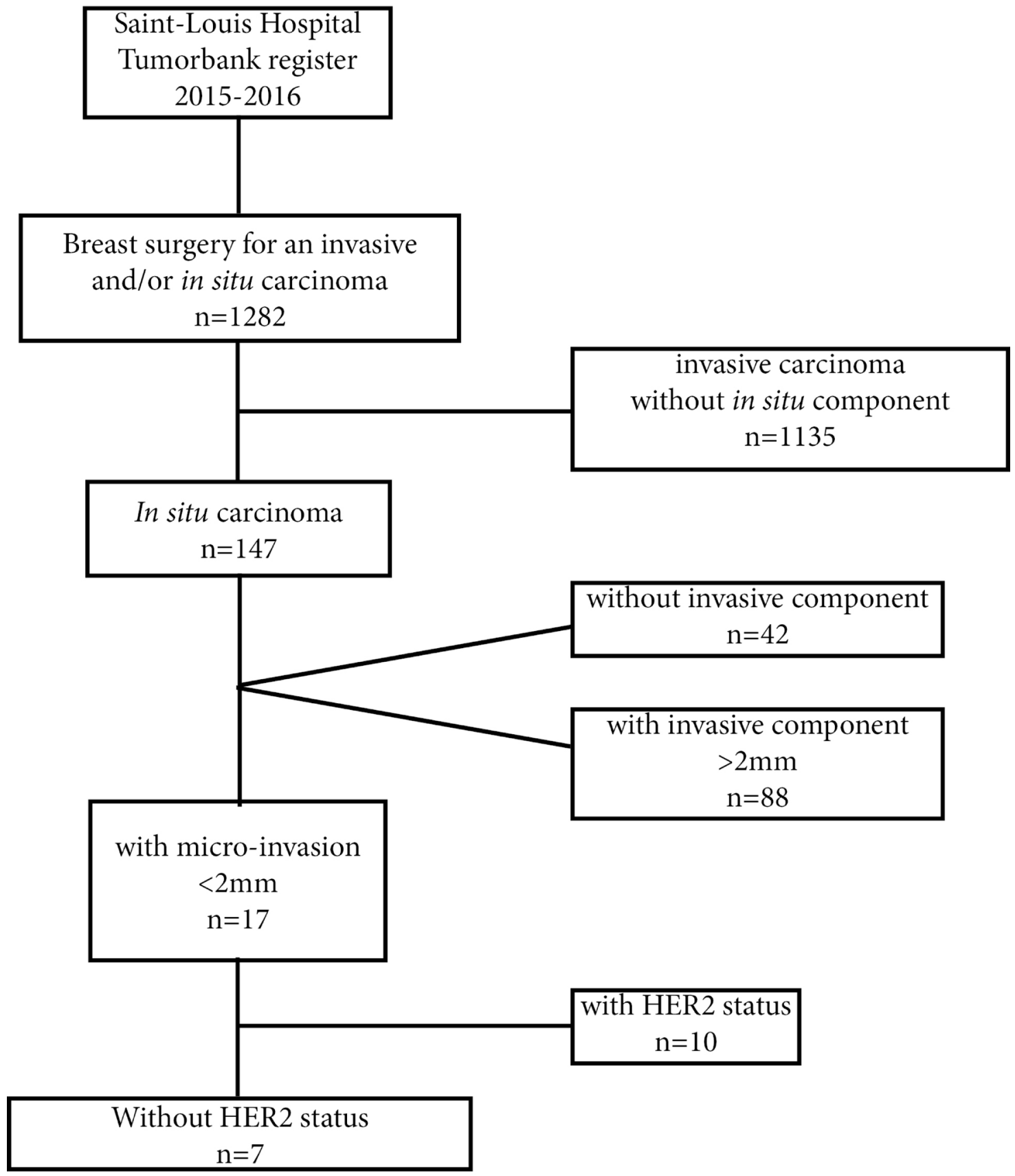

Figure 3: Diagram for selection criteria of the 7 patients with in situ carcinoma and micro-invasive component with undetermined HER2 status. 
Table 2: Assessment of HER2 status on micro-invasive breast cancer using laser-microdissection and ddPCR

\begin{tabular}{lc}
\hline Patient & ddPCR \\
\cline { 2 - 2 } & ratio HER2/RNAseP \\
\hline Patient 1 & 1 \\
Patient 2 & $\mathbf{5 . 6}$ \\
Patient 3 & NE \\
Patient 4 & $\mathbf{2}$ \\
Patient 5 & 1 \\
Patient 6 & 0.7 \\
Patient 7 & 1 \\
\hline
\end{tabular}

NE: not evaluable.

invasive primary tumor since the patient already had a lymph node micrometastasis at diagnosis ( $\mathrm{pN} 1 \mathrm{mi})$, and the level of HER2 amplification, since a ratio HER2/CEP17 over 5 is associated with a higher complete response rate to trastuzumab-based chemotherapy [12]. We finally took into account the patient's own preference to maximally decrease her relapse-risk.
Laser-microdissection enables the selection of cells from solid tumor tissue sections in the same way as flow-cytometry and cell-sorter enable selection from cell suspensions. However laser-microdissection is not fully automatized [13], it produces small quantities of selected cells and micromethods are required for subsequent molecular analyses [14]. ddPCR analyses
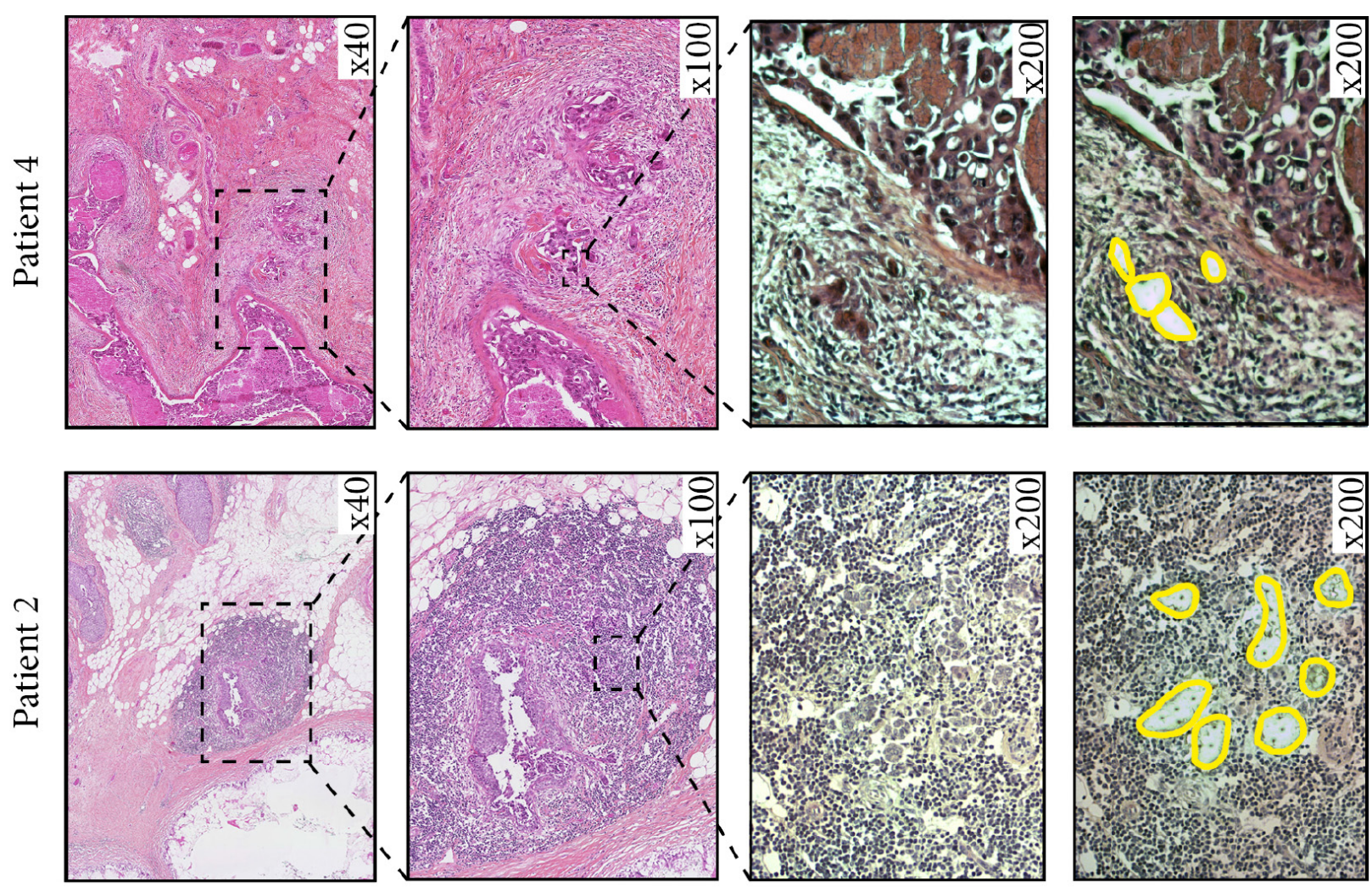

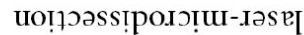
ว.Iоэəg

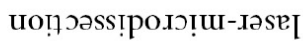
ІәभУ

Figure 4: illustrates two cases of patients with in situ carcinoma and micro-invasion, for whom we performed lasermicrodissection of micro-invasive cells followed by ddPCR, and found an amplified HER 2 status. For patient 2 (left panels), hematein-eosin staining of the primary tumor (upper left panels) shows small foci of micro-invasive ductal carcinoma within a strong inflammatory reaction. Laser-microdissection enables the precise selection of these small foci of cancer cells (lower left panels). For patient 4 (right panels), hematein-eosin staining of the primary tumor (upper left panels) shows typical aspect of extensive ductal carcinoma in situ surrounded by small clusters of mciroinvasion. 
based on the sample dispersion in droplets, followed by nucleic acid amplification of each droplet, enables detection of molecular events expressed in small numbers of cells. In this study, we evidenced the reliability of our method to accurately determine HER2 amplification status in 10 live cells and in 50 cancer cells laser-microselected from formalin-fixed tissue sample. This is sufficient in most cases of microinvasive or micro-metastatic cell clusters.

In the case of our patient with intraductal carcinoma and a single lymph-node micrometastasis identified on the extemporaneous cryo-cut section, we chose to analyse HER2 copy-number-variation on laser-microdissected cells because, for HER2, the level of gene amplification is correlated to protein overexpression [1].

In breast cancer clinical practice, these micromethods of tumor cell dissection and HER2 molecular analysis extend the limits of tumor invasion characterization for the patients' benefit. These micromethods could enable therapy optimization for in situ cancers with microinvasive areas that are too small for immunohistochemistry analyses. HER2 gene analyses are particularly suited to laser-microdissected cells because i) the level of gene amplification is correlated to protein overexpression, and ii) trastuzumab targets HER2 overexpressing tumor cells even in micro-invasive and micro-metastatic breast cancers.

\section{MATERIALS AND METHODS}

\section{Laser-microdissection and DNA processing}

A first experimental control used BT474 cells which HER 2 copy number is known. For the selection of BT474 cells, living cells were spread on a dedicated slide and laser-microdissected one by one, enabling a precise count of the total number of cells. A total number of 1, 5, 10, 20, 50 and 100 cells were tested. Each experiment was performed in triplicate.

A second in situ control used $5 \mu \mathrm{m}$-thick formalinfixed paraffin-embedded tissue sections of breast cancers with known HER2 status. Laser-microdissection was performed to select a precise number of $5,10,20,50$, or 100 cells. On tissue sections of breast cancers with microinvasive component and undetermined HER2 status, the total numbers of invasive cells were counted and a minimum of 50 cells were laser-microdissected. Each experiment was performed in triplicate.

For the patient here studied, laser microdissection was performed on the $5 \mu$ m-thick frozen tissue section of the sentinel lymph node, using a Zeiss Microdissection and Pressure Catapulting system (Zeiss, Munich, Germany), to select cancer cells localized within a lymphatic section under the lymph node capsule. The total laser microdissected area was $21492 \mu \mathrm{m}^{2}$, corresponding to a total of 50 cancer cells.
In all cases, total DNA was extracted from the microdissected cells using DNeasy-Micro-Kit (Qiagen, Courtaboeuf, France), and concentrated in a final volume of $10 \mu \mathrm{L}$.

\section{Droplet-digital PCR method for DNA copy number analysis}

For HER2 gene copy number analyses, total DNA extracted from microdissected tumor cells was used. Total DNA from BT-474 (ductal carcinoma cell line overexpressing HER2) was used as positive control and total DNA from MDA-MB-231 (adenocarcinoma cell line not overexpressing HER2) was used as a negative control. On the 3 different DNA samples, the Droplet Digital Polymerase Chain Reaction (ddPCR) was performed using the QX100 ddPCR workflow system (Biorad, Hercules, CA, USA). The mix contained $20 \mathrm{ng}$ of genomic DNA from microdissected cells, $10 \mu \mathrm{L}$ of So Fast Eva Green Supermix (Bio Rad), $1 \mu \mathrm{L}$ of HER2 probes (Hs00223586 cn, Life Technologies, Foster City, USA) and $1 \mu \mathrm{L}$ Rnase $\bar{P}$ probes (Taqman ${ }^{\circledR}$ copy number Reference Assay, 4403326, Life Technologies) or $1 \mu \mathrm{L}$ Ch17 centromere (CEP17) probes (see Supplementary File 1) per well, and the final volume for the reaction was $20 \mu \mathrm{L}$. Droplets were generated by a QX200 Droplet Generator (Biorad). PCR was carried out on the CFX96 Real Time System (Bio Rad). PCR was performed with an initial denaturing step at $95^{\circ} \mathrm{C}$ for $10 \mathrm{mn}$, followed by 40 cycles of denaturing $\left(95^{\circ} \mathrm{C}\right.$ for $\left.15 \mathrm{~s}\right)$, and annealing $\left(60^{\circ} \mathrm{C}\right.$ for $\left.1 \mathrm{mn}\right)$. A post-amplification melting curve program was initiated by heating to $98^{\circ} \mathrm{C}$ for $10 \mathrm{mn}$ and then cooling down to $12^{\circ} \mathrm{C}$. Each PCR run included a no-template control. The results of ddPCR were generated using QX100 Droplet Reader (Biorad), and analysed using QuantaSoft software (Biorad). The ratio of HER2-positive droplets to RnasePpositive droplets was calculated. A ratio of $0.8-1.2$ was considered as a normal copy number for the HER2 gene.

\section{Ethics approval}

In compliance with French Bioethics-law (2004$800,06 / 08 / 2004)$, the patients had been informed of the research use of the part of their biopsy samples remaining after diagnosis had been established, and did not oppose to it.

\section{Author contributions}

ME and $\mathrm{CB}$ performed the molecular techniques and data analysis. IT and MZ performed the pathological study and provided the study material. LZ provided clinical data. CM provided the study material and performed laser microdissection. FB carried out the virtual slide processing. AB performed surgery and provided clinical data. AJ located financial support, 
provided critical analysis of the data and interpretation, and drafted the manuscript. GB conceived and designed the study, collected the data, performed data analysis and interpretation and drafted the manuscript. CL performed laser microdissection procedures, performed data analysis and interpretation, and drafted the manuscript.

All authors read and approved final version.

\section{ACKNOWLEDGMENTS} editing.

We thank Angela Swaine for English language

\section{CONFLICTS OF INTEREST}

The authors declare no competing interests.

\section{FUNDING}

Inserm, University Paris 7.

\section{REFERENCES}

1. Jacquemier J, Spyratos F, Esterni B, Mozziconacci MJ, Antoine M, Arnould L, Lizard S, Bertheau P, LehmannChe J, Fournier CB, Krieger S, Bibeau F, Lamy PJ, et al. $\mathrm{SISH} / \mathrm{CISH}$ or qPCR as alternative techniques to FISH for determination of HER2 amplification status on breast tumors core needle biopsies: a multicenter experience based on 840 cases. BMC Cancer. 2013; 13:351.

2. Piccart-Gebhart MJ, Procter M, Leyland-Jones B, Goldhirsch A, Untch M, Smith I, Gianni L, Baselga J, Bell R, Jackisch C, Cameron D, Dowsett M, Barrios CH, et al, and Herceptin Adjuvant (HERA) Trial Study Team. Trastuzumab after adjuvant chemotherapy in HER2-positive breast cancer. N Engl J Med. 2005; 353:1659-1672.

3. Swain SM, Baselga J, Kim SB, Ro J, Semiglazov V, Campone M, Ciruelos E, Ferrero JM, Schneeweiss A, Heeson S, Clark E, Ross G, Benyunes MC, Cortés J, and CLEOPATRA Study Group. Pertuzumab, trastuzumab, and docetaxel in HER2-positive metastatic breast cancer. N Engl J Med. 2015; 372:724-734.

4. Wolff AC, Hammond ME, Hicks DG, Dowsett M, McShane LM, Allison KH, Allred DC, Bartlett JM, Bilous M, Fitzgibbons P, Hanna W, Jenkins RB, Mangu PB, et al, and American Society of Clinical Oncology, and College of American Pathologists. Recommendations for human epidermal growth factor receptor 2 testing in breast cancer: American Society of Clinical Oncology/College of American Pathologists clinical practice guideline update. J Clin Oncol. 2013; 31:3997-4013.

5. Belgrader P, Tanner SC, Regan JF, Koehler R, Hindson BJ, Brown AS. Droplet digital PCR measurement of
HER2 copy number alteration in formalin-fixed paraffinembedded breast carcinoma tissue. Clin Chem. 2013; 59:991-994.

6. Zhu Y, Lu D, Lira ME, Xu Q, Du Y, Xiong J, Mao M, Chung HC, Zheng G. Droplet digital polymerase chain reaction detection of HER2 amplification in formalin fixed paraffin embedded breast and gastric carcinoma samples. Exp Mol Pathol. 2016; 100:287-293.

7. Otsuji K, Sasaki T, Tanaka A, Kunita A, Ikemura M, Matsusaka K, Tada K, Fukayama M, Seto Y. Use of droplet digital PCR for quantitative and automatic analysis of the HER2 status in breast cancer patients. Breast Cancer Res Treat. 2017; 162:11-18.

8. Wang X, Wu Y, Song X, Sun C, Wu C, Feng H. Human epidermal growth factor receptor 2 amplification detection by droplet digital polymerase chain reaction in formalinfixed paraffin-embedded breast and gastric cancer samples. J Cancer Res Ther. 2017; 13:730-734.

9. American Joint Committee on Cancer (AJCC). AJCC Cancer Staging Manual. 8th ed. New York: Springer; 2017.

10. Curigliano G, Burstein HJ, P Winer E, Gnant M, Dubsky P, Loibl S, Colleoni M, Regan MM, Piccart-Gebhart M, Senn HJ, Thurlimann B, André F, Baselga J, et al, and St. Gallen International Expert Consensus on the Primary Therapy of Early Breast Cancer 2017. Ann Oncol. 2017; 28:1700-1712.

11. de Nonneville A, Goncalves A, Zemmour C, Classe JM, Cohen M, Lambaudie E, Reyal F, Scherer C, Muracciole X, Colombo PE, Giard S, Rouzier R, Villet R, et al. Benefit of adjuvant chemotherapy with or without trastuzumab in pT1ab node-negative human epidermal growth factor receptor 2-positive breast carcinomas: results of a national multi-institutional study. Breast Cancer Res Treat. 2017; 162:307-316.

12. Singer CF, Tan YY, Fitzal F, Steger GG, Egle D, Reiner A, Rudas M, Moinfar F, Gruber C, Petru E, Bartsch R, Tendl KA, Fuchs D, et al, and Austrian Breast and Colorectal Cancer Study Group. Pathological Complete Response to Neoadjuvant Trastuzumab Is Dependent on HER2/CEP17 Ratio in HER2-Amplified Early Breast Cancer. Clin Cancer Res. 2017; 23:3676-3683.

13. Bertheau P, Plassa LF, Lerebours F, de Roquancourt A, Turpin E, Lidereau R, de The H, Janin A. Allelic loss detection in inflammatory breast cancer: improvement with laser microdissection. Lab Invest. 2001; 81:1397-1402.

14. Bousquet G, El Bouchtaoui M, Leboeuf C, Battistella M, Varna M, Ferreira I, Plassa LF, Hamdan D, Bertheau P, Feugeas JP, Damotte D, Janin A. Tracking sub-clonal TP53 mutated tumor cells in human metastatic renal cell carcinoma. Oncotarget. 2015; 6:19279-89. https://doi. org/10.18632/oncotarget.4220. 